\title{
Recovery, science and human rights
}

Received 15 March 2012; Revised 18 March 2012; Accepted 6 April 2012; First published online 22 May 2012

Key words: Evidence, human rights, recovery, UN-Convention on the rights of persons with disabilities.

Commentary on: Slade M, Leamy M, Bacon F, Janosik M, Le Boutillier C, Williams J, Bird V (2012). International differences in understanding recovery: systematic review. Epidemiology and Psychiatric Sciences.

'Research is better than rhetoric' was a bold announcement and the title of an editorial on 'recovery, psychosis and psychiatry' by Slade \& Hayward (2007). It pointedly expressed an idea quite prevalent among professionals thinking about policy change and system transformation, namely that for recovery-orientation to survive and gain impact research evidence is essential. With their systematic review of published recovery conceptualizations Slade et al. have admirably proven how much can be done with scientific vigour. It is impressive how this group of determined researchers are able to scientifically evaluate the vast and diverse body of international writing on recovery and their results are certainly most valuable for a fast moving field.

On the other hand, the reference to 'implications for policy and practice' swiftly brings to mind the examples on how changes do not regularly occur from within the mainstream scientific field of psychiatry or because of the new scientific evidence, but from other forces within psychiatry and society. Mental health reform in the 1960s and 1970s had much to do with a society that was not willing to accept the dire circumstance in asylums shown through narratives, reports, films and prominently echoed in popular media. Journalists, politicians and policy-makers from diverse backgrounds played essential roles in the transformation to community care. Another essential influence on health system changes is money and of course the current debate on recovery also talks about possible financial implications. In addition to lack of clear definition and lack of scientific evidence, concerns by mental health professionals are directed at the possible misuse of the concept in order to cut

Address for correspondence: Professor M. Amering, Department of Psychiatry and Psychotherapy, Medical University of Vienna, Wien, Austria

(Email: michaela.amering@meduniwien.ac.at) services (Roberts \& Hollins, 2007) and further aggravate the already deplorable mental health resource situation. At the same time, there is an understanding that through successful collaborations between different stakeholders the essential expertise of lived experience in practice and research (Wallcraft et al. 2009) should provide the mental health field with a multiperspective evidence-base for policy and development (Rose et al. 2006) in order to strengthen its position within the health system and society at large (Wallcraft et al. 2011).

The fact that empowered service users and family carers have been successful in finding ways to understand and influence the professional mental health system, is a key for the current developments of the recovery model from a bottom-up movement into a top-down policy approach. Most conceptual and political considerations and decisions have evolved from collaborations between people with and without a lived experience of mental health problems and psychiatric services (Amering \& Schmolke, 2009). Many of the most influential publications on recovery have been written by users and ex-users and work-groups that have brought together individuals with and without personal experiences. It would be great if Slade et al.'s data would allow an analysis of the authors of the researched publications in this regard as well as other information on the authors' background, like the rate of nursing researchers among them, who seem to play a growing role in research on recovery.

The CHIME framework (Connectedness, Hope and optimism about the future, Identity, Meaning in life, and Empowerment) is the major result of the original as well as the updated review and refers to recovery processes. Apart from the question whether this kind of acronym is in itself indicative of the wish to stay within the established ways of conceptualizing, formulating and disseminating mental health concepts, the CHIME framework seems to me to point towards a reconciliation between the contents of the 'clinical' and 'personal' recovery definitions in that they include illness-related aspects as well as talk about the life independent of illness. The descriptions of e.g. meaning - the $\mathrm{M}$ in CHIME - is reported to include 
'many themes related to finding meaning in life and also meaning associated with the mental illness experience' and empowerment as 'related both to a sense of empowerment within mental health services ... and also included becoming an empowered member of society'. This strongly reminds me of our most recently emerging qualitative data on stigma resistance and schizophrenia following our quantitative study (Sibitz et al. 2011). The analysis confronts us with the recurring notion of 'ordinary AND extraordinary' in that generic aspects of gaining self-esteem and resilience go hand-in-hand with having to deal with the very specific challenges of the stigma of the diagnosis of schizophrenia and the experience of psychosis.

The conceptual background of Slade et al.'s review paper concentrates on opposing paradigms and the differentiation between 'clinical' and 'personal' recovery. Slade et al. state that 'clinical recovery has emerged from professional-led research and practice, and involves returning to normal' and put in contrast a brief definition of personal recovery involving 'living as well as possible', a definition that shares with the current SAMSHA definition the absence of the word illness. This is different in the other definition cited by Slade et al. in the context of personal recovery Bill Anthony's prominent definition of recovery from 1993. In order to make the point that the concentration on the suggested tension between opposing paradigms runs the risk of oversimplification and fails to capture the diversity of concepts and interests of 'professionals' as well as people with a lived experience, I would like to refer to Bill Anthony's actual personal experience. Anthony (2006), a prominent academic in psychiatric rehabilitation, published a personal report about his own illness, multiple sclerosis - MS, and the assistance he has been receiving in connection with it. He contrasts the 'MS-Community' as exemplary with respect to instilling courage and hope, continually providing information and opportunities for exchange, and for never questioning a person's ultimate freedom of choice with the medical profession of psychiatry not acting with full respect and support for its patients. He maintains the vision that what is possible for MS should also be possible for severe psychiatric conditions, but sees a great deal of work and transformation ahead in order to realize this vision. Instead of a differentiation between 'clinical' and 'personal' recovery his account stresses deplorable differences between psychiatry and medicine with regard to patients and human rights.

Another major result of this and the former review are the similarities between minority and majority (Leamy et al. 2011) and similarities across the international literature. This is in line with my personal experience with contact to the user/survivor communities in different cultures as well as trialogue experiences in different parts of the world (www.trialogue.co; Amering et al. 2012) with amazing and sometimes overwhelming similarities under very diverse circumstances.

The evidence gaps identified in the review are expressed in a call for the use of sophisticated established research methods in order to address the issues of how recovery unfolds over time and to understand the relationship between recovery domains, like the one comprised in CHIME, and clinical domains of outcome. Slade et al. also ask for empirical evidence for the relative contribution of mental health services for recovery. Although we should certainly not shy away from these essential research responsibilities, it is also imperative to appreciate a clear view of the already existing evidence as summarized recently by Warner (2010) in his affirmative answer to the question 'Does the scientific evidence support the recovery model?'. Warner specifically refers to data on the longterm course of schizophrenia supporting optimism, evidence regarding the role of work and supported employment for recovery, participatory decisionmaking and peer support. He also addresses the complex topic of empowerment as a means against the negative effects of internalized stigma and calls for further controlled studies on empowerment-oriented interventions.

This in turn brings to mind another example of how the results of strategic considerations rather than operationalized definitions or classical evidence base are currently exerting a possibly transformative impact on health and mental health care and rehabilitation in terms of user empowerment. I am referring to the fact that people who doubt the validity and utility of psychiatric disease labels were willing and able to use their lived experience with mental distress and psychiatric treatment and their political engagement to work with the wider disability movement. Their successful efforts resulted in the expressed inclusion of disabilities resulting from psychiatric disorders in the UN-Convention on the rights of persons with disabilities.

With my thanks and congratulations to Mike Slade and his group for their scientific vigour as well as their will to keep the research close to the reality of peoples' experiences and goals. I would like to suggest that human rights as specifically expressed as the rights of persons with disabilities might serve as a central focus of orientation in our work. In order to meet the very complex challenges as outlined by the debates around recovery we might profit from a simple formulation for our efforts. To guarantee the human rights of people who come in contact with psychiatry could be the main focus for all of us in the international mental 
health community, be it as peers, clinicians, family and friends, advocates, therapists or in our research work as scientists.

\section{Amering}

Department of Psychiatry and Psychotherapy, Medical University of Vienna, Wien, Austria

\section{References}

Amering M, Schmolke M (2009). Recovery in Mental Health. Reshaping Scientific and Clinical Responsibilities.

Wiley-Blackwell: London.

Amering M, Mikus M, Steffen S (2012). Recovery in Austria: Mental health trialogue. International Review of Psychiatry 24, 11-18.

Anthony W (2006). Personal accounts: what my MS has taught me about severe mental illnesses. Psychiatric Services 57, 1081-1082.

Leamy M, Bird V, Le Boutillier C, Williams J, Slade M (2011). A conceptual framework for personal recovery in mental health: systematic review and narrative synthesis. British Journal of Psychiatry 199, 445-452.
Roberts G, Hollins S (2007). Recovery: our common purpose? Advances in Psychiatric Treatment 13, 397-399.

Rose D, Thornicroft G, Slade M (2006). Who decides what evidence is? Developing a multiple perspectives paradigm in mental health. Acta Psychiatrica Scandinavica 113 (Suppl. 429), 109-114.

Sibitz I, Unger A, Woppmann A, Zidek T, Amering M (2011). Stigma resistance in patients with schizophrenia. Schizophrenia Bulletin 37, 316-323.

Slade M, Hayward M (2007). Recovery, psychosis and psychiatry: research is better than rhetoric. Acta Psychiatrica Scandinavica 116, 81-83.

Wallcraft J, Amering M, Schrank B (Eds.) (2009). Handbook of Service User Involvement in Mental Health Research. Wiley: London.

Wallcraft J, Amering M, Freidin J, Davar B, Froggatt D, Jafri H, Javed A, Katontoka S, Raja S, Rataemane S, Steffen S, Tyano S, Underhill C, Wahlberg H, Warner R, Herrman $H$ (2011). Partnerships for better mental health worldwide: WPA recommendations on best practices in working with service users and family carers. World Psychiatry 10, 229-236.

Warner R (2010). Does the scientific evidence support the recovery model? Editorial. Psychiatrist 34, 3-5. 